\title{
Assessment and characterisation of common renal masses with CT and MRI
}

\author{
Leo Pallwein-Prettner • Daniel Flöry • Claus Raphael Rotter • Kurt Pogner • \\ Gerhard Syré • Claudia Fellner • Ferdinand Frauscher • Friedrich Aigner • \\ Frens Steffen Krause • Franz Fellner
}

Received: 18 November 2010 /Revised: 12 May 2011 / Accepted: 28 June 2011 / Published online: 17 July 2011

(C) European Society of Radiology 2011

\begin{abstract}
Objective Owing to the widespread use of abdominal imaging studies the detection rate of solid renal masses has increased, and an accurate characterisation of imaging features of renal masses has become more essential for case management.

Method and results MR imaging (MRI) and computed tomography (CT) are frequently used modalities for detection and differentiation of renal masses. This article gives a review of imaging characteristics of benign and malignant renal masses, discussing their appearance in CT and MR imaging. Advanced MR techniques like diffusion-weighted imaging and apparent diffusion coefficient (ADC) mapping, which have shown promising results in the differentiation between benign and malignant renal lesions, will be introduced. Conclusion MRI and CT are useful in the characterisation and estimation of the prognosis for renal masses.
\end{abstract}

\footnotetext{
L. Pallwein-Prettner $(\bowtie) \cdot D$. Flöry $\cdot$ F. Fellner

Department of Radiology, General Hospital Linz,

Krankenhausstrasse 9,

4020 Linz, Austria

e-mail: leo.pallwein-prettner@bhs.at

C. R. Rotter $\cdot$ K. Pogner $\cdot$ F. S. Krause

Department of Urology, General Hospital Linz,

Linz, Austria

G. Syré

Department of Pathology, General Hospital Linz,

Linz, Austria

C. Fellner

Institute of Radiology, University Medical Center Regensburg,

Regensburg, Germany

F. Frauscher $\cdot$ F. Aigner

Department of Radiology, Medical University Innsbruck,

Innsbruck, Austria
}

Keywords Humans · Kidney diseases · Kidney masses · Magnetic resonance imaging $\cdot$ Computed tomography

\section{Introduction/epidemiology}

The detection rate of renal masses has increased in the last decades owing to the widespread use of CT and MRI [1]. Therefore, an accurate characterisation of renal masses is essential to ensure appropriate case management. Renal masses can be divided into cystic and solid lesions [2]. The most common are cysts in up to $27 \%$ of patients over 50 years [3]. CT- or MRI-enhancing masses are classified as solid or complex cystic. Eighty-five percent of expansive solid masses are malignant [4]. Therefore, a solid, enhancing mass must be considered malignant unless proven otherwise. Renal cell carcinoma (RCC) is the most common malignant tumour with a rising incidence of about $3 \%$ per year since 1975. The most common subtype of RCC is the clear cell RCC (synonym: common or conventional RCC) with $65 \%$ of renal cortical tumours. Further subtypes are papillary (basophilic and eosinophilic) and chromophobe RCCs with about $25 \%$ of renal cortical tumours. Clear-cell RCC causes $90 \%$ of metastases of all renal malignancies [5, 6]. Other malignant masses include transitional cell carcinoma (TCC), lymphoma (primary and more frequent secondary), metastases from carcinoma and primary/secondary sarcoma. Primary tumours of the lung, breast and gastrointestinal tract are the most common sources of renal metastases [7].

Benign tumours account for approximately $20 \%$ of all solid renal cortical tumours, and renal oncocytoma is the most common solid tumour type $[8,9]$.

Non-neoplastic renal masses include inflammatory pseudotumours with and without abscess formation, renal 
infarct, haematoma and replacement lipomatosis with coexistent xanthogranulomatous pyelonephritis $[10,11]$.

\section{Examination protocol}

The examination protocols of CT and MR are abundantly described elsewhere and we refer to the current literature [12-15].

CT A renal CT is performed in 3-4 phases: the native, arterial (20- to 40 -s delay), the venous (100- to 150 -s delay) and the excretory phase (180- to 300 -s delay). In order to reduce radiation exposure, different low-dose protocols and a reduction of contrast phases have been reported [14].

MRI MR examinations are performed with dedicated body (array) coils and must include T1-weighted gradient-echo (GRE, in- and opposed-phase) and T2-weighted turbo spin echo (TSE) sequences. Dynamic gadolinium-enhanced images are obtained in late arterial (20-s delay), nephrographic (80-s delay) and excretory phases (180-s delay). As in CT, MR urograms can be obtained ideally with thick-slab single-shot T2-weighted TSE.

The use of furosemide for forced diuresis and a further distension of the collecting system and for a consecutive reduction in the $\mathrm{T} 2 *$ effects of the concentrated contrast material is optional $[13,15]$.

Concerning diffusion-weighted imaging (DWI) [16], different authors have shown the value of apparent diffusion coefficients (ADCs) for characterising renal masses. In these studies, renal tumours had significantly lower ADCs compared with benign cysts, and solid enhancing tumours had significantly lower ADCs compared with non-enhancing necrotic or cystic regions [17, 18]. They concluded that ADC measurements may aid in differentiating subgroups of renal masses, particularly benign cystic lesions from cystic renal cell cancers (Fig. 1).
Fig. 1 Presentation of diffusion-weighted images (DWI; b-value: 800) and apparent diffusion coefficient (ADC) maps in different entities: Upper row demonstrates bright signal on DWI (a; b-value: 800 ) and low signal on an ADC map (b) in the case of a clear cell renal cell carcinoma (RCC), with heterogeneous pattern on T2-weighted image (c). The signal decrease in the ADC map is considered to be a marker of high cell density in the tumour. Middle row demonstrates bright signal on the ADC map (d) in a polycystic kidney. T2-weighted image shows different intensities in the cysts (arrow in e). The cysts were graded as Bosniak I-II. Lower row demonstrates bright signal on DWI (f; b-value: 800 ) in a case of xanthogranulomatous pyelonephritis (see also Fig. 10). The ADC map (g) showed no signal loss, which could be explained by interstitial oedema but no indication of increased cell densitiy, which can be helpful in the differentiation of an inflammatory from a neoplastic tissue alteration. Contrast-enhanced T1-weighted image shows strong enhancement of the pelvic wall (arrow in h)

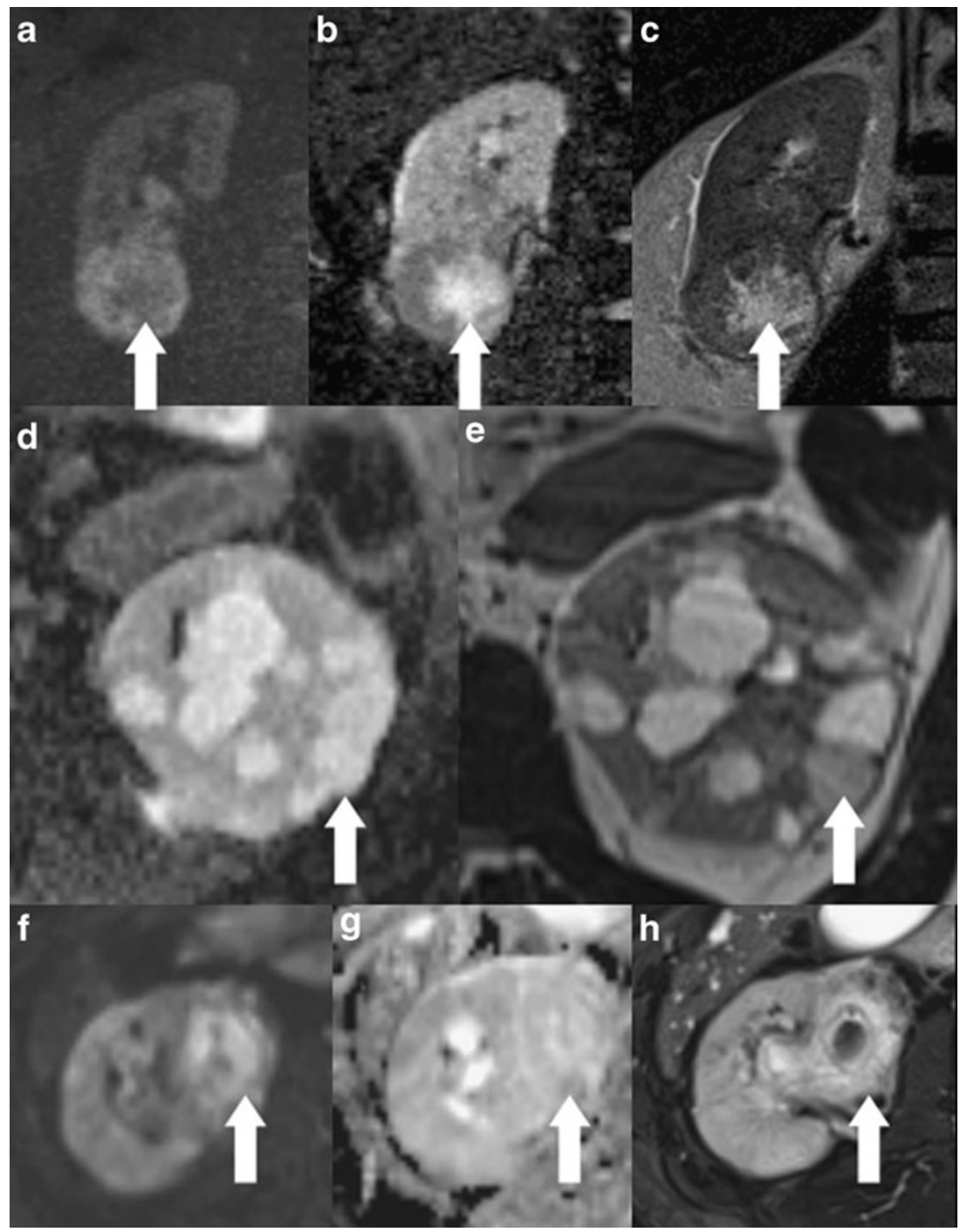




\section{Imaging parameters of renal masses}

These imaging parameters should be helpful in the characterisation of renal masses focussing especially on differentiation between cystic and solid lesions [19].

I. Detection of lesions: Because of better soft-tissue contrast the tumour detection rate seems better with $\mathrm{MR}$, but according to the literature, especially in renal lesions with a diameter of more than $2 \mathrm{~cm}$, CT shows a similar detection rate [20].

II. Size, shape and contour: Renal masses with a diameter of $<4 \mathrm{~cm}$ are defined as small renal masses. The smaller the mass is, the greater the chance that it is benign [1]. In a report $46 \%$ of masses that were less than $1 \mathrm{~cm}$ in diameter were benign, as were $22 \%$ of those that were 1 to $2.9 \mathrm{~cm}$ in diameter and $20 \%$ of those that were 3 to $3.9 \mathrm{~cm}$ in diameter [21]. Among malignant masses, greater size correlates with higher pathological grade $[4,22-$ 24]. As in many other malignancies, unsharpened borders of a solid tumour are nearly always a sign of malignancy with the exception of inflammatory cysts and bleeding angiomyolipoma.

III. Growth rate: Growth rate of small renal masses is typically low (2 to $4 \mathrm{~mm}$ per year) and seems to be similar for masses subsequently found to be malignant (renal cell carcinoma) and those found to be benign (oncocytoma) [26]. Masses without growth were about as likely to be malignant $(83 \%)$ as those that grew (89\%) [27]. There are no definable clinical or radiological characteristics to predict growth [22].

IV. Tissue consistency: Areas of macroscopic fat within a renal mass are usually diagnostic of angiomyolipoma with a very few exceptions. In rare cases the additional presence of calcification in a fat-containing lesion can indicate a malignant condition [28, 29]. A small number of angiomyolipomas do not contain fat and remain a diagnostic dilemma because differentiation from malignant renal neoplasm is impossible [30]. On the other hand, a few cases of RCC have been reported where macroscopic fat and calcifications were present [31].

Presence of central necrosis may be helpful in the diagnosis of RCC, a finding that is very rare in angiomyolipoma [32]. Intratumoral haemorrhage has a variable appearance depending on the stage of degradation of the component blood products. Subacute to chronic haemorrhage generally demonstrates high signal intensity on both T1- and T2weighted images. Chronic haemorrhage, containing haemosiderin, is typically hypointense on both T1- and T2weighted images [33]. Intratumoral bleeding is sometimes hard to depict with $\mathrm{CT}$, while calcifications can hardly be seen on MRI.
V. Imaging characteristics of common renal masses

The imaging characteristics of common renal masses are listed in Table 1.

1. Simple/Complex cyst:

The Bosniak classification system is used to graduate cystic masses: [34]

- Bosniak I: Benign simple cyst, hairline-thin wall, no septa, calcifications or solid components. Water density, no contrast enhancement.

- Bosniak II: Benign cyst, may contain few hairline-thin septa. Fine calcification or slightly thickened calcification in wall or septa. Uniformly high-attenuation lesions $(<3 \mathrm{~cm})$, sharply marginated, no enhancement, are included in this group.

- Bosniak IIF: Increased number of hairline-thin septa. Minimal enhancement in hairline-thin smooth septum or wall, minimal thickening of the septa or wall. Possibly thick and nodular calcification, no contrast enhancement. No enhancing soft-tissue components. Totally intrarenal nonenhancing high-attenuation renal lesions that are $3 \mathrm{~cm}$ or larger are also included in this category. These lesions are generally well marginated.

- Bosniak III: Indeterminate cystic masses with thickened irregular walls or septa, enhancement can be seen.

- Bosniak IV: Clearly malignant cystic masses, additionally with enhancing soft-tissue components adjacent to but independent of the wall or septa.

$C T$ It is helpful to differentiate category I, III and IV cysts. Depending on the size and location, it is critical to differentiate between complicated cysts of categories II and III [35].

The so-called pseudoenhancement is defined as an artificial elevation of the Hounsfield unit measurements of a renal cyst measured on the contrast-enhanced CT images and is thought to be secondary to the image reconstruction algorithm used to adjust for beam-hardening effects. This pseudoenhancement of small intraparenchymal cysts can lead to an upgraded Bosniak cyst classification with major implications for prognosis and clinical management. Also, calcification and high-densitiy fluid of cysts can complicate the differentiation between Bosniak II and III cysts $[2,31]$.

MRI Simple cysts are homogeneous hyperintense lesions with a thin wall on T2-weighted images (Fig. 2). Complex cysts have septa and solid nodules with low signal on T2weighted images due to haemorrhagic or proteinaceous content (Fig. 3). On T1-weighted images simple cysts are hypointense relative to the normal renal parenchyma. 


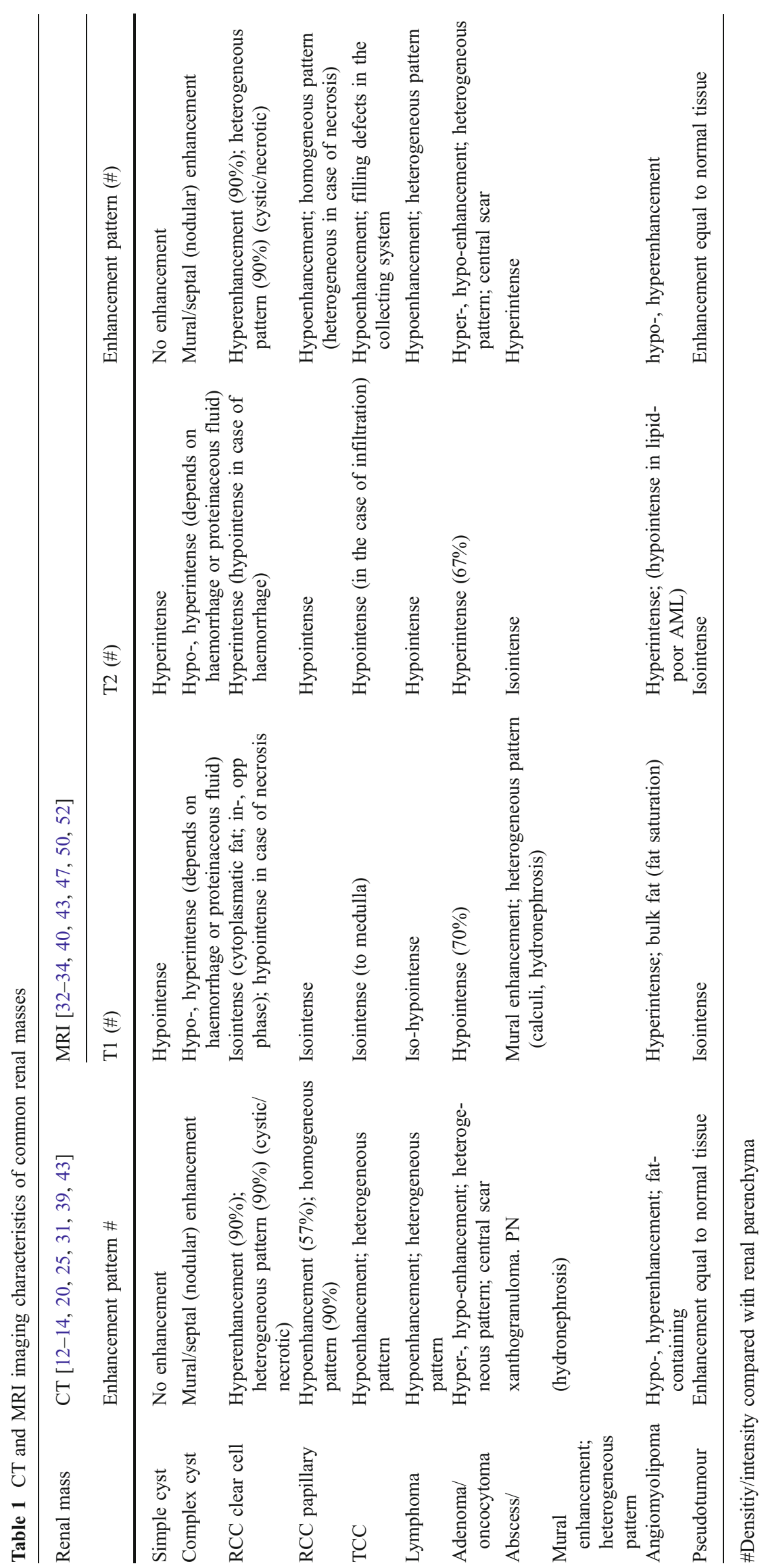


Fig. 2 MRI presentation of typical image characteristics of a simple cyst (Bosniak I): hyperintense on T2-weighted images (T2; arrow in a), hypointense on T1-weighted images (T1; arrow in b), no contrast media enhancement in T1 (arrow in c), and bright on the diffusionweighted images (ADC map; arrow in $\mathbf{d}$ )
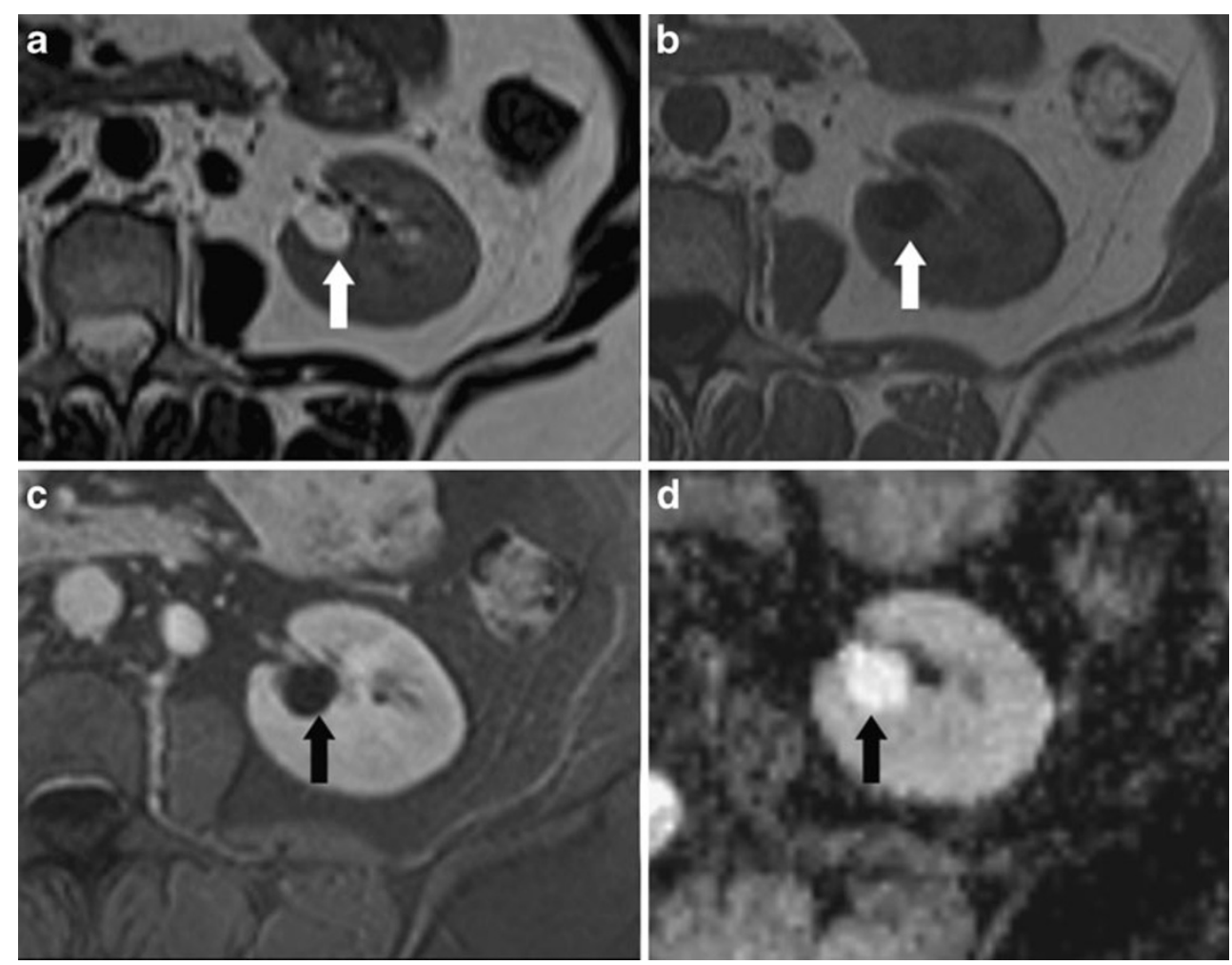

Fig. 3 MRI presentation of typical image characteristics of a complex cyst (Bosniak IV): hyperintense with hypointense areas on T2- (arrow in a), hypo- and isointense in T1- (arrow in b), focal contrast media enhancement on T1-weighted (arrow in c), and heterogeneous pattern on the ADC map (arrow in d)
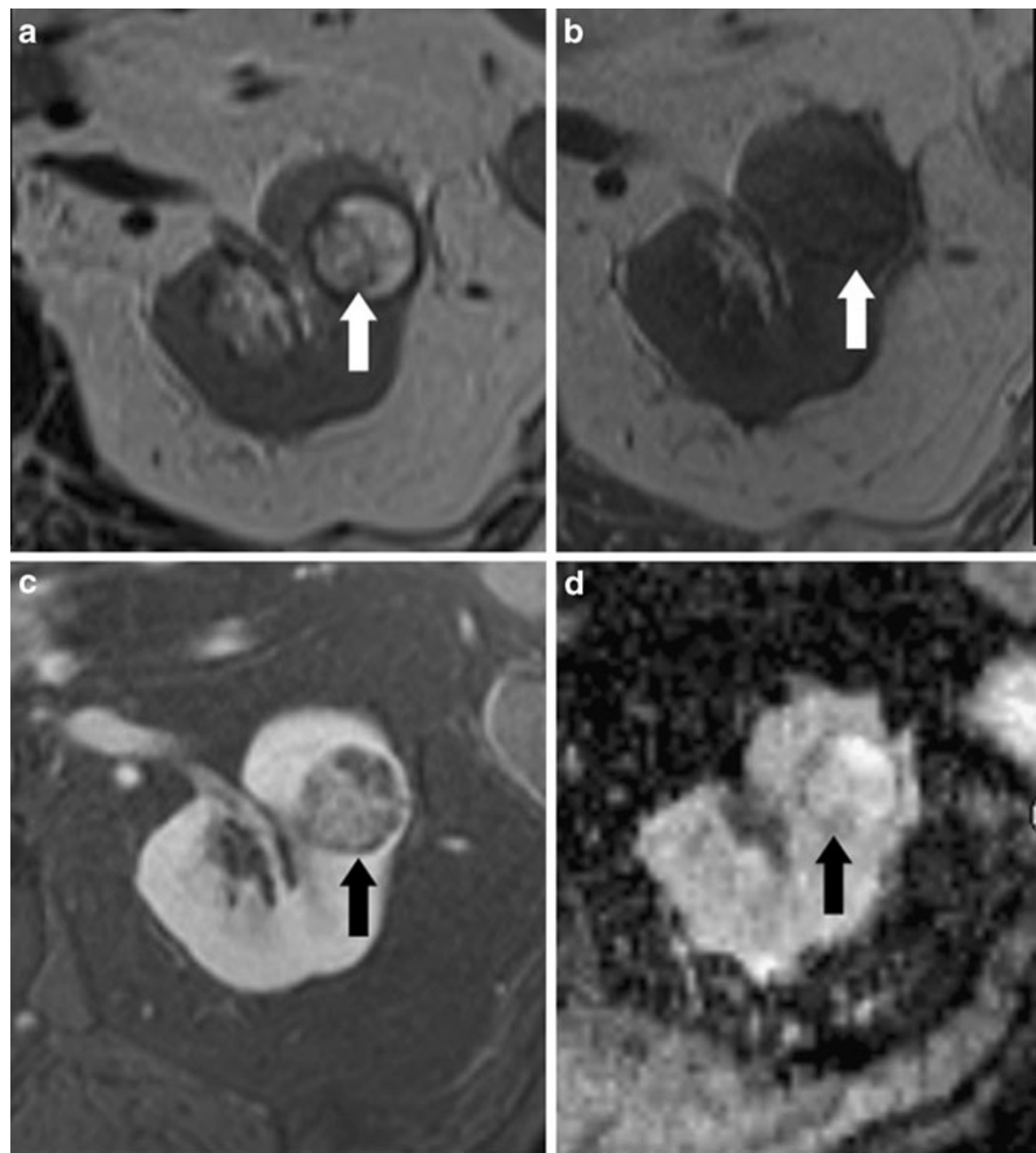
Increased signal may indicate haemorrhage or proteinaceous fluid [32].

Israel et al. compared $\mathrm{CT}$ and MRI in the evaluation of cystic renal masses by using the Bosniak classification system. $\mathrm{CT}$ and MRI findings were similar for most cystic renal masses. In some cases, however, MRI may depict additional septa, thickening of the wall and/or septa, or enhancement, which may lead to an upgraded Bosniak classification [34]. Nevertheless, it is helpful to be aware that the Bosniak criteria have been defined and validated for CT and not for MRI. Therefore, the Bosniak criteria have to be used carefully used in relation to magnetic resonance imaging.

Despite the use of contrast-enhanced ultrasound (CEUS) in the differential diagnosis of renal masses still being under debate, complex cysts of the kidney are probably the best indication for renal CEUS. CEUS helps to depict blood flow perfusion within the wall, septa and solid components. Furthermore, CEUS is applicable in patients with impaired kidney function or ureteric obstruction, which may be contraindications for contrast-enhanced CT or MRI [36].

\section{RCC (clear cell or common type)}

The Fuhrman grading system categorises clear cell carcinoma into four groups (Fig. 4). Its use has been expanded to other subtypes (e.g., papillary RCC). The following tumours have a poorer prognosis: high-grade carcinoma, clear cell RCC, sarcomatoid and rhabdoid differentiations of clear cell RCC [37, 38].

$C T$ Ninety percent of clear cell RCCs are hypervascular with a heterogeneous enhancing pattern of mixed enhancing solid soft-tissue components and low-attenuation necrotic or cystic areas $[13,39]$. Clear cell carcinomas can be predominantly cystic. Renal vein tumour thrombus can be seen with aggressive higher stage tumours.

MRI Appearance varies depending on the presence of haemorrhage and necrosis. On T1-weighted images clear cell RCC most frequently demonstrates a signal intensity as renal parenchyma. Central necrosis is typically seen as a homogeneous hypointense area in the centre of the mass on
Fig. 4 Multimodal presentation of a common type RCC on CT and MRI: CT (upper row): isodense in the native phase (arrow in a), hypervascular in the arterial phase with areas of necrosis (arrow in b) and early wash-out in the venous phase (arrow in c). MRI (middle and lower row): heterogeneous appearance on T2-weighted (arrow in d) and T1-weighted native (arrow in e) because of haemorrhage and necrosis, heterogeneous pattern on the ADC map (arrow in $\mathbf{f}$ ), hyperenhancement in the arterial phase with areas of necrosis (arrow in $\mathbf{g}$ ), early wash-out in the venous phase (arrow in $\mathbf{h}$ ), and a tumour thrombus with contrast media enhancement reaching the renal vein and inferior vena cava (arrow in i)

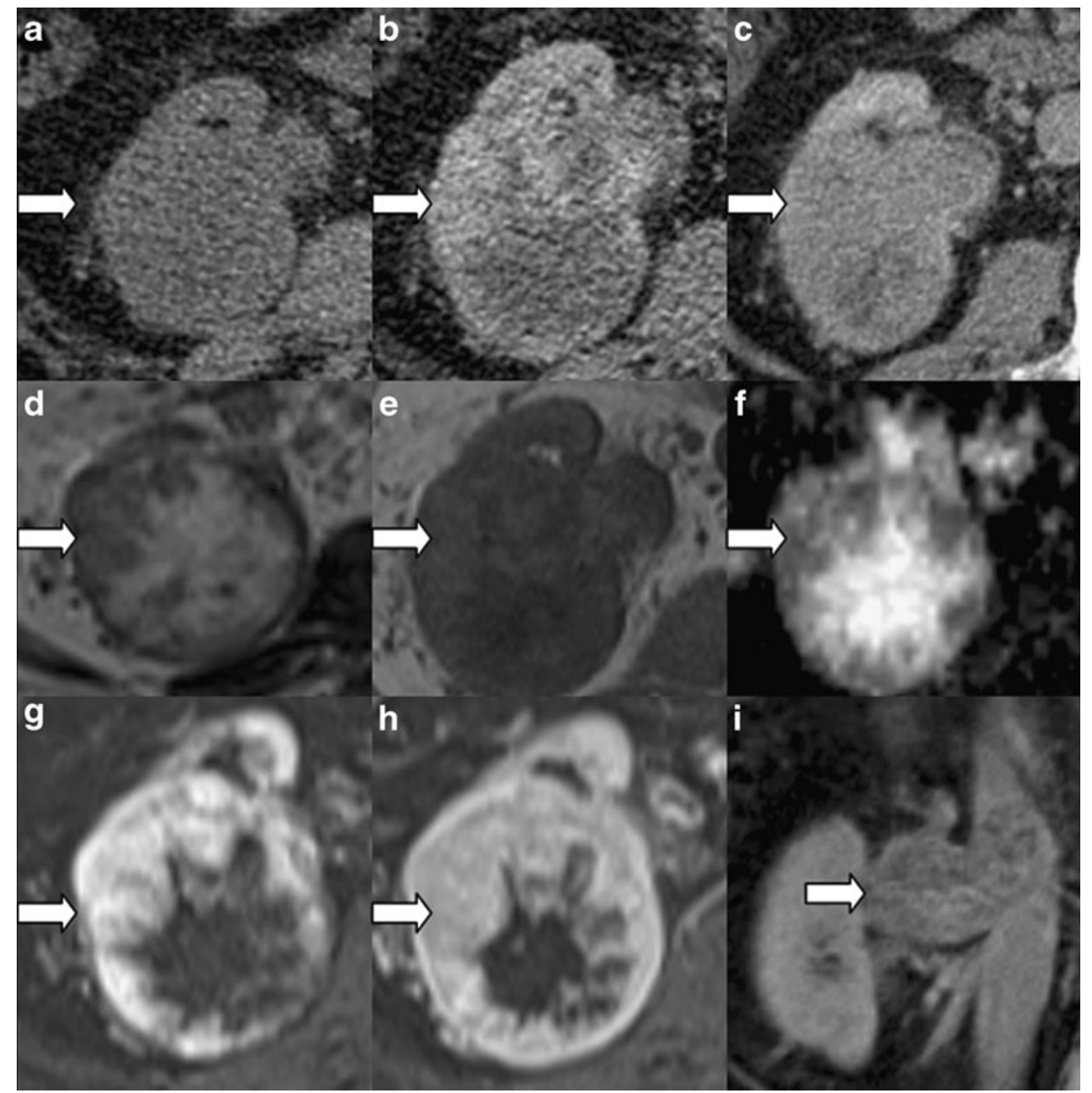


T1-weighted images. On T2-weighted images an increased signal intensity is found. Loss of signal within the solid portions of the clear cell RCCs on opposed-phase images compared with in-phase images is due to cytoplasmic fat and has been observed in up to $60 \%$ of these tumours [ 30 , 32]. Clear cell RCC tends to be hypervascular, with heterogeneous enhancement during the arterial phase [32].

\section{RCC (papillary and chromophobe type)}

Papillary RCC accounts for approximately $10 \%-15 \%$ of all RCCs and may be multifocal (Fig. 5). Chromophobe renal tumours account for approximately $4-11 \%$ of RCCs [32].

$C T$ Seventy-five percent of papillary RCCs are hypovascular, and $90 \%$ of all papillary tumours demonstrate a homogeneous or peripheral enhancement pattern. Chromophobe tumours often demonstrate a moderate degree of enhancement [13, 39].

MRI Papillary RCC demonstrates homogeneous low signal intensity on T2-weighted images with homogeneous lowlevel enhancement after i.v. gadolinium administration. Chromophobe RCC may show cystic changes within a solid tumour. Central necrosis may be absent even in very large chromophobe carcinomas. Imaging features can be identical to those of clear cell RCC [32, 40, 41].

\section{TCC}

Transitional cell carcinoma (Fig. 6) accounts for $90 \%$ of all tumours arising from the renal pelvic urothelium and is divided into papillary (more common) and non-papillary types. TCC is frequently multifocal and may involve any part of the collecting system. Haematogenous spread is less common than with RCC, but lymphatic metastases occur early. Only $2-4 \%$ of patients with bladder cancer develop upper tract TCC, but $40 \%$ of patients with upper tract TCC develop bladder cancer. Diagnosis of upper tract TCC is heavily dependent on imaging. Stage is the main predictor of prognosis in comparison to tumour grade [32, 42].

CT CT urography allows assessment of a non-functioning kidney that is superior to excretion urography and nodal and distant metastases. The shape of the kidney is usually preserved even in the presence of large tumours. Hydronephrosis proximal to the lesion is usually present unless the collecting system is completely filled by tumour. If the renal sinus is obliterated by tumour, the appearance may mimic the so-called faceless kidney [44].

MRI On T1-weighted images TCCs are typically isointense relative to the renal medulla. Enhancement of a focal filling defect in the collecting system is strongly suggestive of a TCC. Differentiation between blood clots and enhancing filling defects may be possible using subtracted data sets. TCC is typically a hypo-enhancing mass, although focal hyper-enhancement may occur.

T2-weighted images show hypointense filling defects in the collecting system. Infiltrative TCC can be seen on single-shot T2-weighted images as a hypointense soft-tissue mass infiltrating the renal parenchyma.

\section{Lymphoma}

Extranodal spread of lymphoma (Fig. 7) often affects the genitourinary system, with the kidneys being the most commonly involved organs. Primary renal lymphoma is rare, and non-Hodgkin's lymphoma is much more common than Hodgkin's. Growth of lymphomatous cells occurs in

Fig. 5 Imaging presentation of a papillary (upper row) and a chromophobe (lower row) RCC. Papillary RCC (a: CT venous phase; b: T2-weighted; c: T1-weighted, venous phase) as well as chromophobe RCC (d: CT native; e: CT, arterial phase; e: CT, venous phase) show a hypoenhancement in the arterial (arrow in e) and venous phase (arrows in $\mathbf{a}, \mathbf{c}$ and $\mathbf{f}$ ), and they are often hypo-/isointense on T2-w (arrow in b) in comparison to normal renal parenchyma

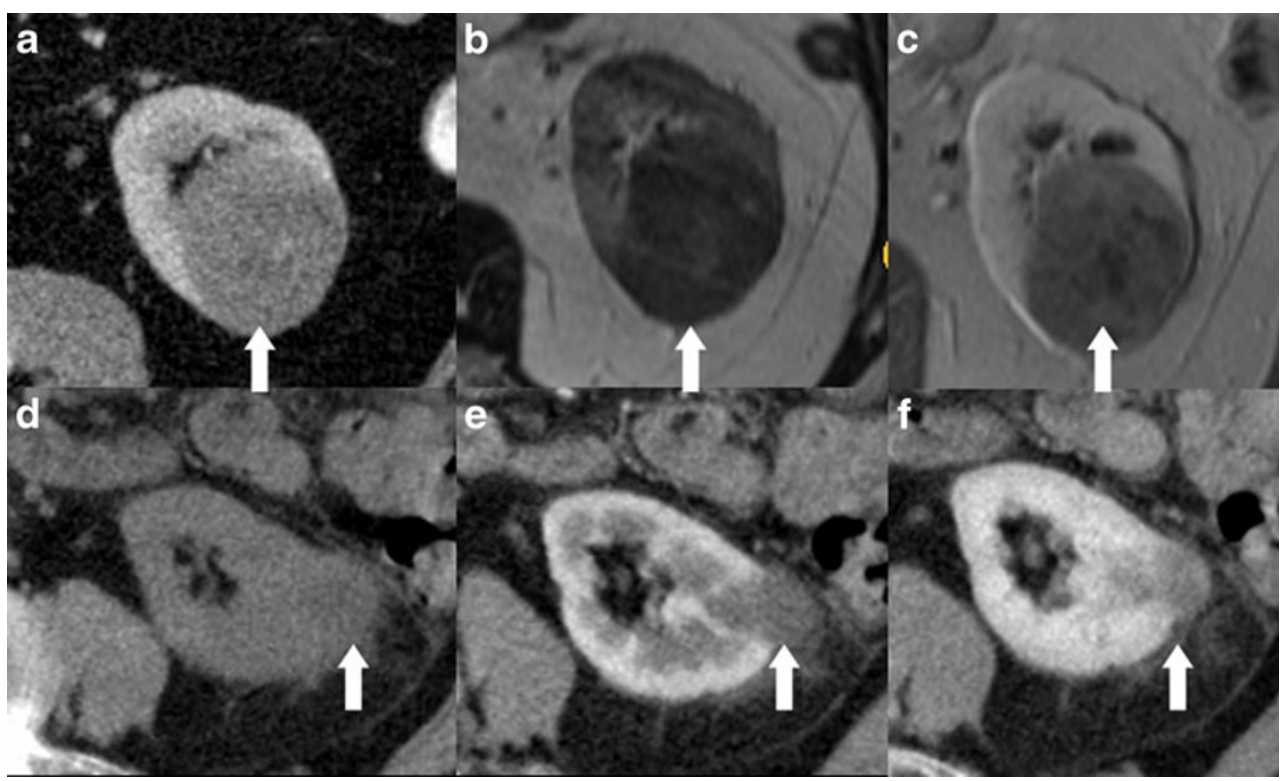




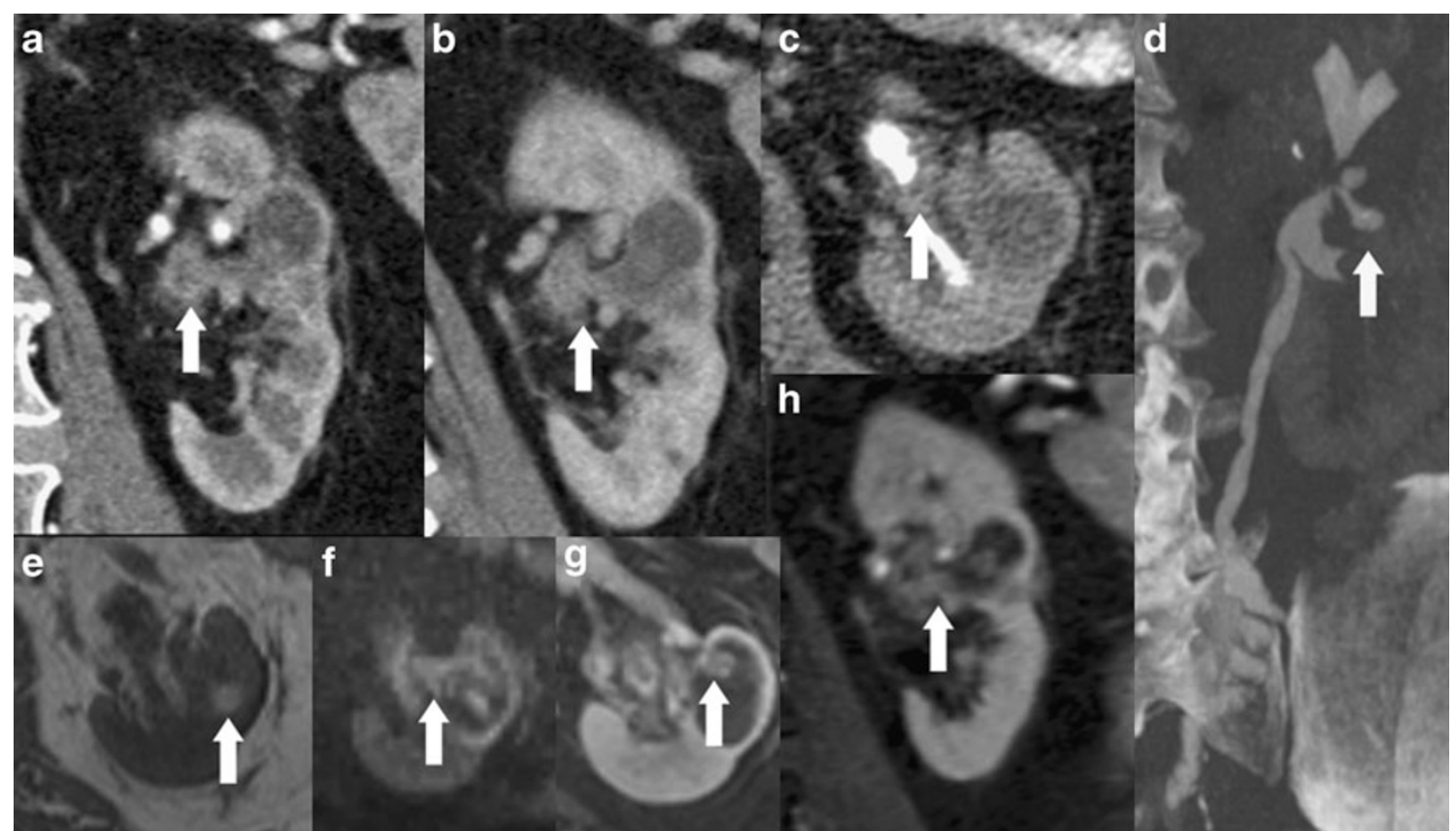

Fig. 6 Imaging presentation of an infiltrating papillary transitional cell carcinoma (TCC) on CT (upper row; a-d) and MRI (lower row; $\mathbf{e}-\mathbf{h})$. On CT there is an enhancing mass in the renal sinus surrounding the neck of the middle calyx (arrows in $\mathbf{a}$ and $\mathbf{b}$ ) with a filling defect in the calyceal neck in the excretory phase (arrow in $\mathbf{c}$ ) and a calyceal amputation in the CT urogram (arrow in d). On MRI the dilated calyx shows bleeding (arrow in e) and suspicious findings on diffusionweighted imaging (arrow in f) with a clearly detectable enhancing mass along the calyceal neck (arrows in $\mathbf{g}$ and $\mathbf{h}$ ) the interstitium, with the nephrons, collecting ducts and blood vessels serving as a framework for tumour expansion, which produces the following patterns [45]:

- multiple poorly enhancing masses $(60 \%)$
- retroperitoneal tumours directly invading the kidneys $(25-30 \%)$

- infiltrative pattern with bilateral renal enlargement without disruption of the renal contour and perirenal soft-tissue masses
Fig. $7 \mathrm{CT}$ imaging presentation (courtesy of Siegfried Schwab, University Hospital Erlangen, Germany; with permission) of renal lymphoma with unilateral (arrows in $\mathbf{a}-\mathbf{c}$ ) and bilateral (arrows in d) hypoenhancing focal masses with diffuse renal swelling and perirenal oedema. Small masses can be found in the cortex and with signs of infiltration of the perirenal space (arrow in $\mathbf{c}$ )

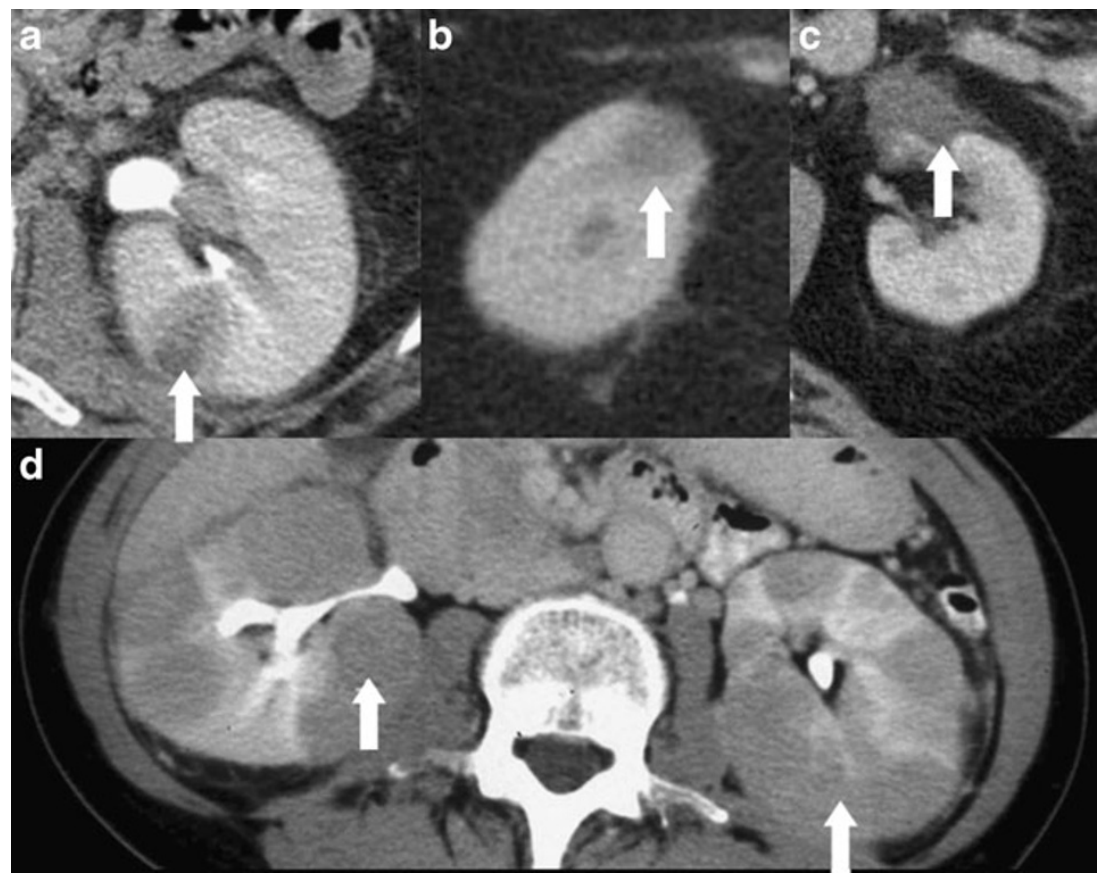


- cystic lesions and tumours predominantly affecting the renal sinus and collecting system are uncommon

Image-guided percutaneous biopsy is essential for diagnostic confirmation to avoid unnecessary nephrectomy. Following treatment, imaging findings may resolve with minimal residual scarring [32].

CT Contrast-enhanced CT remains the technique of choice for the detection, diagnosis, staging and monitoring of renal lymphoma [46, 47].

MRI Besides the morphological patterns already mentioned, lymphomatous masses are, relative to the renal cortex, iso- or slightly hypointense on T1-weighted images and hypointense on T2-weighted images. Minimal heterogeneous enhancement is seen on early and delayed gadolinium-enhanced MR images in retroperitoneal masses and renal involvement $[32,48]$.

\section{Angiomyolipoma}

Angiomyolipomas (Fig. 8) are hamartomas containing varying proportions of fat, smooth muscle and thick-walled blood vessels. Tumours larger than $4 \mathrm{~cm}$ carry an increased risk of potentially life-threatening haemorrhage (Wunderlich syndrome), which has been reported in up to $10 \%$ of these patients [32].

$C T$ Lipid-containing angiomyolipoma can be easily detected with $\mathrm{CT}$.

However, angiomyolipoma may contain very small quantities of fat, which can be overlooked if the mass is not carefully evaluated. When a small amount of fat is suspected in a renal mass, an unenhanced CT examination with thin sections and, if necessary, a pixel analysis, is the most sensitive test [31, 49].

Lipid-poor angiomyolipoma presents a diagnostic dilemma and cannot be differentiated from RCC. Zhang et al.

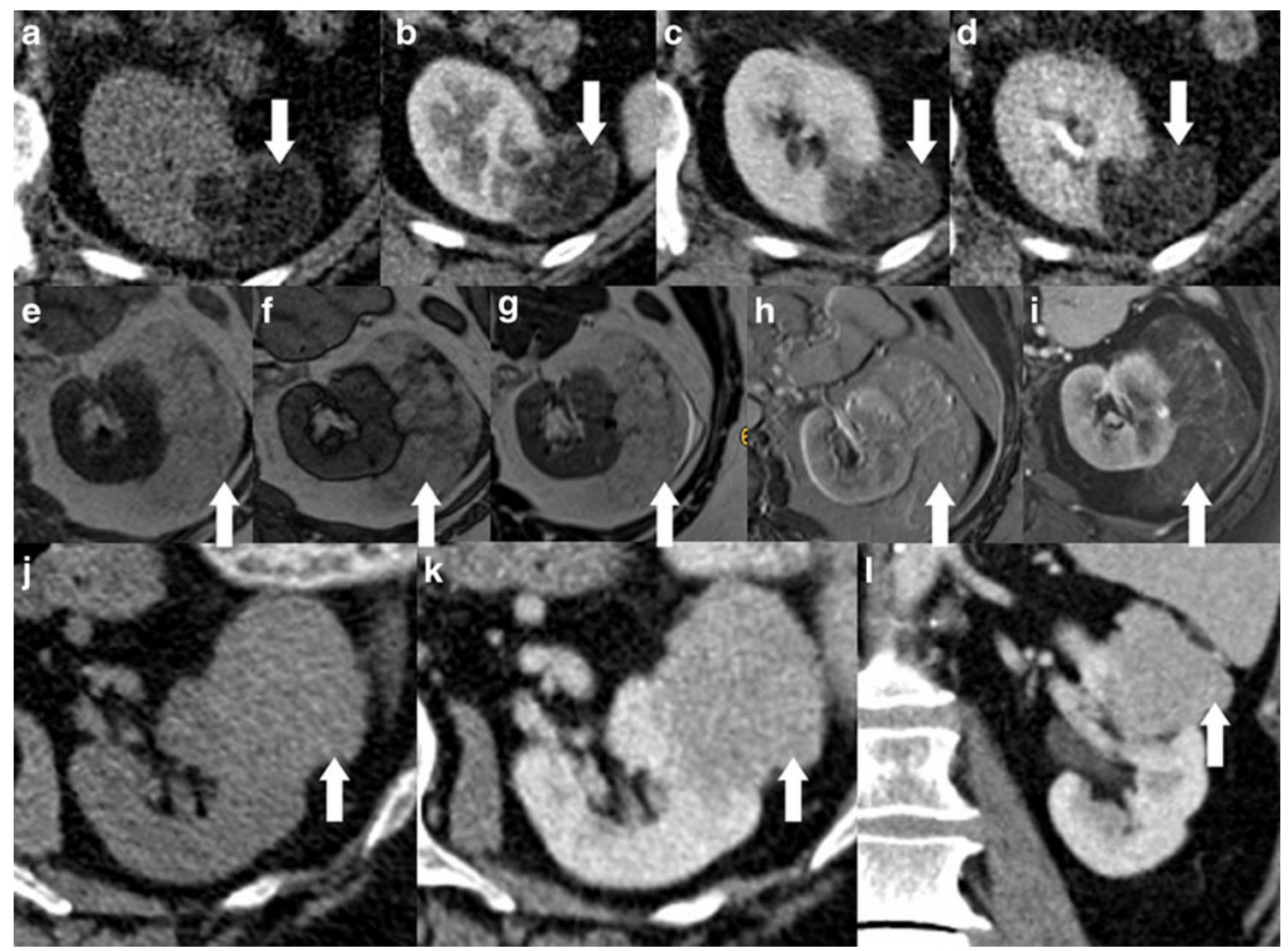

Fig. 8 Imaging presentation of angiomyolipoma (AML) in CT (upper and lower row) and MRI (middle row). On CT (upper row) lipidcontaining AML shows bulk fat in the native (arrow in a) and moderate enhancement in the arterial (arrow in b), venous (arrow in c) and excretory phase (arrow in d). On MRI (middle row) another lipidcontaining AML shows streaky signal alteration on in- and opposed- phase T1-weighted imaging (arrows in $\mathbf{e}$ and $\mathbf{f}$ ), heterogeneous pattern with high signal intensity on TSE T2 (arrow in g), a moderate enhancement on T1 (arrow in $\mathbf{h}$ ), and a clear signal loss on the T1weighted image with fat saturation (arrow in i). On CT (lower row) a lipid-poor AML is not clearly distinguishable from other renal masses in the native (arrow in i) and venous phase (arrows in $\mathbf{j}$ and $\mathbf{k}$ ) 
described a homogeneous pattern and a moderate enhancement of lipid-poor angiomyolipomas [13].

MRI Lipid-containing angiomyolipomas show a higher signal intensity than renal parenchyma on T1-weighted images. Demonstration of bulk fat within an angiomyolipoma can be achieved by applying a selective fatsuppression pulse. Opposed-phase imaging shows a characteristic India ink artifact at the interface between the mass and the normal renal parenchyma. The signal loss can be helpful for the diagnosis of lipid-poor angiomyolipomas, but clear cell RCC can also show small amounts of intracellular fat. The presence of central necrosis suggests the diagnosis of RCC, a finding that is very rare in angiomyolipoma. Lipid-poor angiomyolipomas frequently demonstrate homogeneous low signal intensity relative to the renal parenchyma on T2-weighted images. Angiomyolipomas can show different degrees of enhancement depending on the amount of vascularised tissue components they contain $[32,50,51]$.

However, all the mentioned imaging characteristics are not specific enough to make a confident diagnosis of a nonfat-containing angiomyolipoma. In some cases, biopsy of the renal mass may be indicated to make a definitive diagnosis of an angiomyolipoma and to avoid surgery [31].

\section{Oncocytoma}

Oncocytomas (Fig. 9) account for 3-7\% of solid renal masses. They may be multicentric, bilateral or metachronous in a minority of cases. A stellate central area of fibrosis or hyalinised connective tissue with compressed blood vessels, the so-called central scar, is observed in up to $54 \%$ of cases. Based on imaging findings a proper differentiation between oncocytoma and RCC is not possible [32].

CT Oncocytoma remains a diagnostic challenge. Zhang et al. found that oncocytoma tended to show a homogeneous and hypervascular pattern. A central scar can be seen in large oncocytoma [13].

MRI Appearance is variable and non-specific. Oncocytomas are typically spheric and well-defined masses. Relative to the renal cortex, they have lower signal intensity on T1-weighted images in approximately $70 \%$ and higher signal intensity on T2-weighted images in up to $67 \%$. The central scar (when present) can be seen as a stellate area of high signal intensity on T2-weighted images and of low signal intensity on T1weighted images with delayed gadolinium enhancement. A well-defined hypointense capsule can be seen surrounding the tumour in almost one-half of renal oncocytomas. However, the presence of a pseudocapsule is non-specific and can be seen in up to $60 \%$ of RCCs as well [32, 52].

\section{Pyelonephritis/abscess/xanthogranulomatous pyelone- phritis/renal infarction}

Bacterial pyelonephritis (PN) usually is an ascending infection from the lower urinary tract and can affect one or both kidneys. Haematogenous spread of bacteria is rare and usually affects both kidneys.

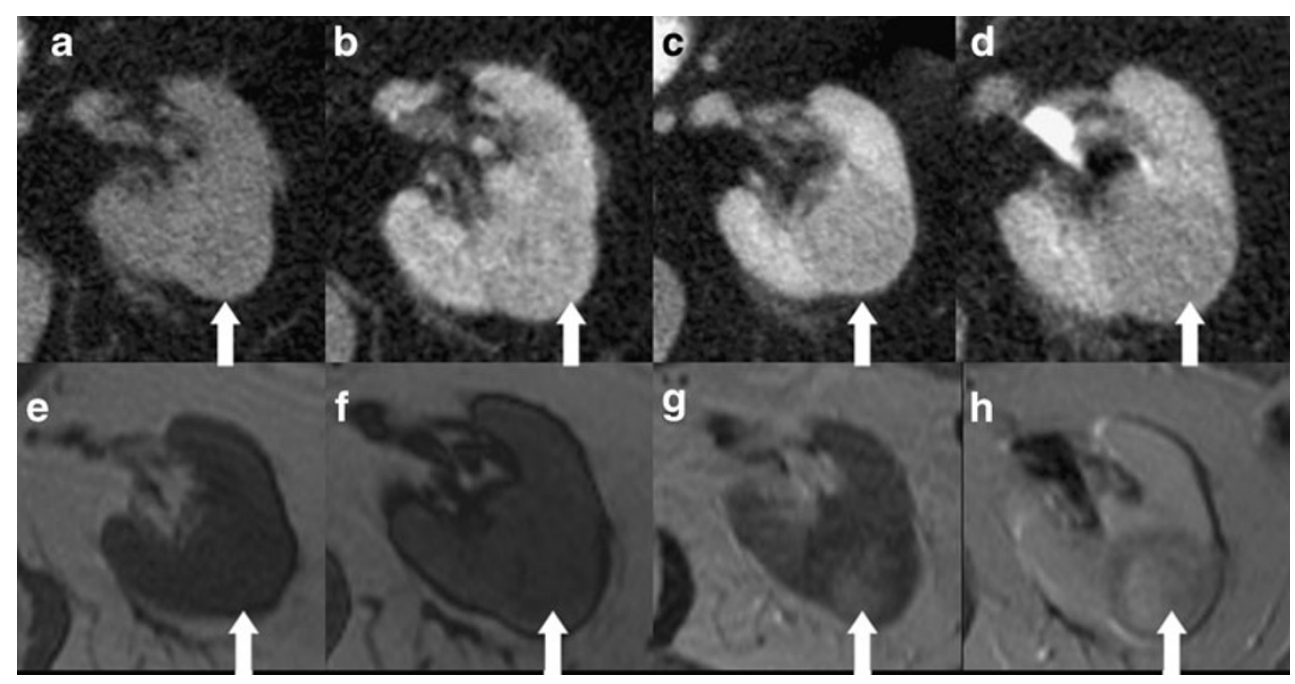

Fig. 9 Imaging presentation of adenoma on CT (upper row) and MRI (lower row) in one patient. CT shows a native isodense mass (arrow in a) with a hyperenhancement in the arterial phase (arrow in b), and an early wash-out in the venous (arrow in c) and excretory (arrow in d) phases. MRI shows a non-lipid-containing mass on the in- and opposed-phase T1-weighted imaging (arrows in $\mathbf{e}$ and $\mathbf{f}$ ) with a heterogeneous appearance in T2- (arrow in $\mathbf{g}$ ) and a heterogeneous contrast media enhancement in T1-weighted image (arrow in h). Based on imaging features alone, this mass cannot be differentiated from RCC 
Xanthogranulomatous pyelonephritis (XP) (Fig. 10) results from severe chronic infection causing diffuse renal destruction. Risk factors include female gender and diabetes. Most patients have nephrolithiasis, and staghorn calculi are found in $50 \%$ of patients. The more common diffuse form is characterised by extensive involvement of the renal parenchyma. The focal form of the disease may be misinterpreted as a renal neoplasm; the presence of a staghorn calculus, appropriate clinical presentation and the characteristic imaging findings strongly suggest the diagnosis [32]. CT is helpful in the detection of calculi.

$C T$ In the case of PN unenhanced CT may appear normal, but acute bacterial nephritis most commonly manifests as one or more wedge-shaped areas or streaky zones of lesser enhancement that extend from the papilla to the renal cortex. Abscesses can be identified in CT as round or geographic low-attenuation collections with no central enhancement, but an enhancing rim (pseudo-capsules with wall thicknesses and frequent nodularity). Diminished enhancement may surround the abscess (halo sign) during the nephrographic phase. Extraparenchymal collections can extend into adjacent structures (e.g., psoas muscle).

MRI The value of MR imaging for early diagnosis of pyelonephritis is still under debate.

Heterogeneous enhancement of renal tissue can also be seen with MR imaging. Probably DWI is helpful because of its high senstivity in the detection of parenchymal oedema.

Magnetic resonance imaging findings of abscesses are similar to those of CT and include renal oedema, haemorrhage, renal enlargement, abscesses and perinephric fluid [53]. Abscess cavities show intermediate signal on T1weighted images and high signal intensity on T2-weighted images. Cavity walls may show marked gadolinium enhancement. Calculi may be seen as areas of signal void within the collecting system $[32,54]$.

Renal infarction (RI) can have various causes, including thromboembolism, renal artery thrombosis, vasculitis, shock and trauma.
Fig. 10 Imaging presentation of xanthogranulomatous pyelonephritis (XP) and bacterial pyelonephritis (PN) on $\mathrm{CT}$ and MRI: XP on CT (upper row): a pelvic stone is clearly visible with a diffuse thickening of the pelvic wall, which shows enhancement in the arterial (arrow in a) and venous (arrow in b) phase. The CT urogram (arrow in c) shows the hydronephrosis owing to an obstruction at the level of the ureteropelvic junction. XP on MRI (middle row): the thickening of the pelvic wall is clearly detectable on T1-weighted (arrow in d) and T2-weighted (arrow in e) images, and an enhancement of the pelvic wall in $\mathrm{T} 1$ in the venous (arrow in f) phase. Contrast-enhanced MRI urogram (g) enables a similar presentation of the upper urinary tract in comparison to the $\mathrm{CT}$ urogram. PN on MRI (lower row): ADC mapping shows a decreased signal (arrow in $\mathbf{h}$ ) and DWI (b-value: 800) a heterogeneous pattern of renal parenchyma (arrow in i). In the venous phase small nonenhanced subcapsular areas are detectable (arrow in j). MR urogram shows no hydronephrosis in this case of ascending PN (arrow in $\mathbf{k}$ )

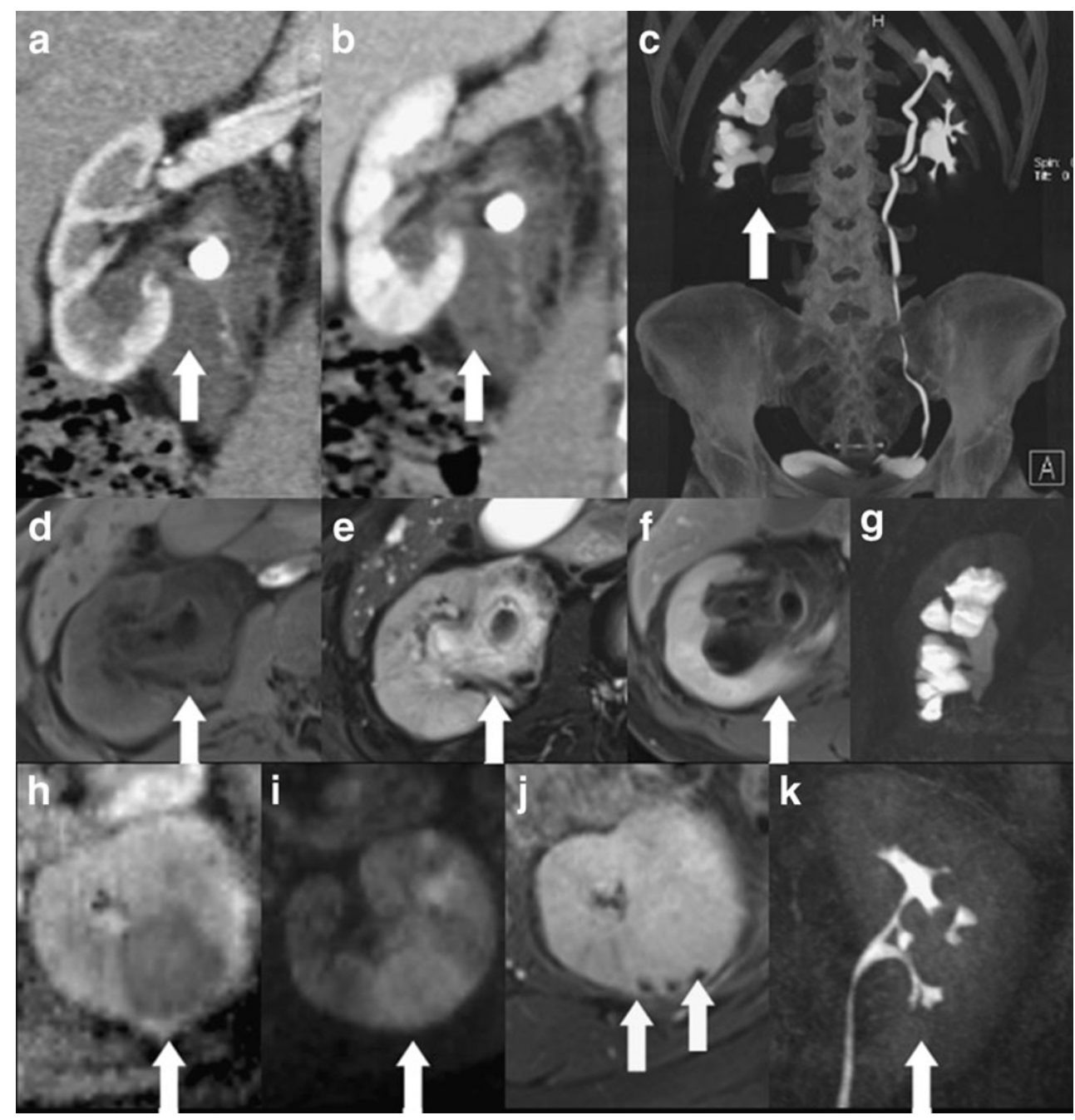


$C T$ CT shows a swelling of the kidney, usually with perirenal fluid. Other findings are subcapsular haematoma, mass effect or a focal area of renal enlargement, and a thickened renal fascia. On post-contrast images a demarcation of the wedgeshaped infarcted areas is possible. The ischaemic areas are mainly located in the columns of the kidney contrary to inflammatory alterations, which can be located in the renal pyramids in the case of ascending infection.

MRI On T1- and T2-weighted MR images, the signal intensity of the infarcted area is usually lower than that of the non-infarcted area owing to interstitial oedema and haemorrhage, with a loss of corticomedullary differentiation. In the follow-up signal intensity increases progressively with both sequences because of coagulation necrosis and interstitial haemorrhage. Post-contrast T1-weighted images clearly demonstrate wedge-shaped infarcted areas. The non-infarcted portion of the involved kidney may have higher signal intensity than the opposite uninvolved kidney on T2-weighted images and post-contrast T1-weighted images because of acute tubular necrosis and interstitial oedema at the margin of the infarct or reperfusion injury. With development of cortical atrophy and organising fibrosis (after weeks) the signal intensity of the infarcted area decreases again. The extent and distribution of the infarcted areas at MR imaging correlate well with $\mathrm{CT}$ and angiography [55].

VI. Clinical management/role of percutaneous renal mass biopsy
Fig. 11 Clinical flow chart of renal masses (modified according to Gill et al. [19])

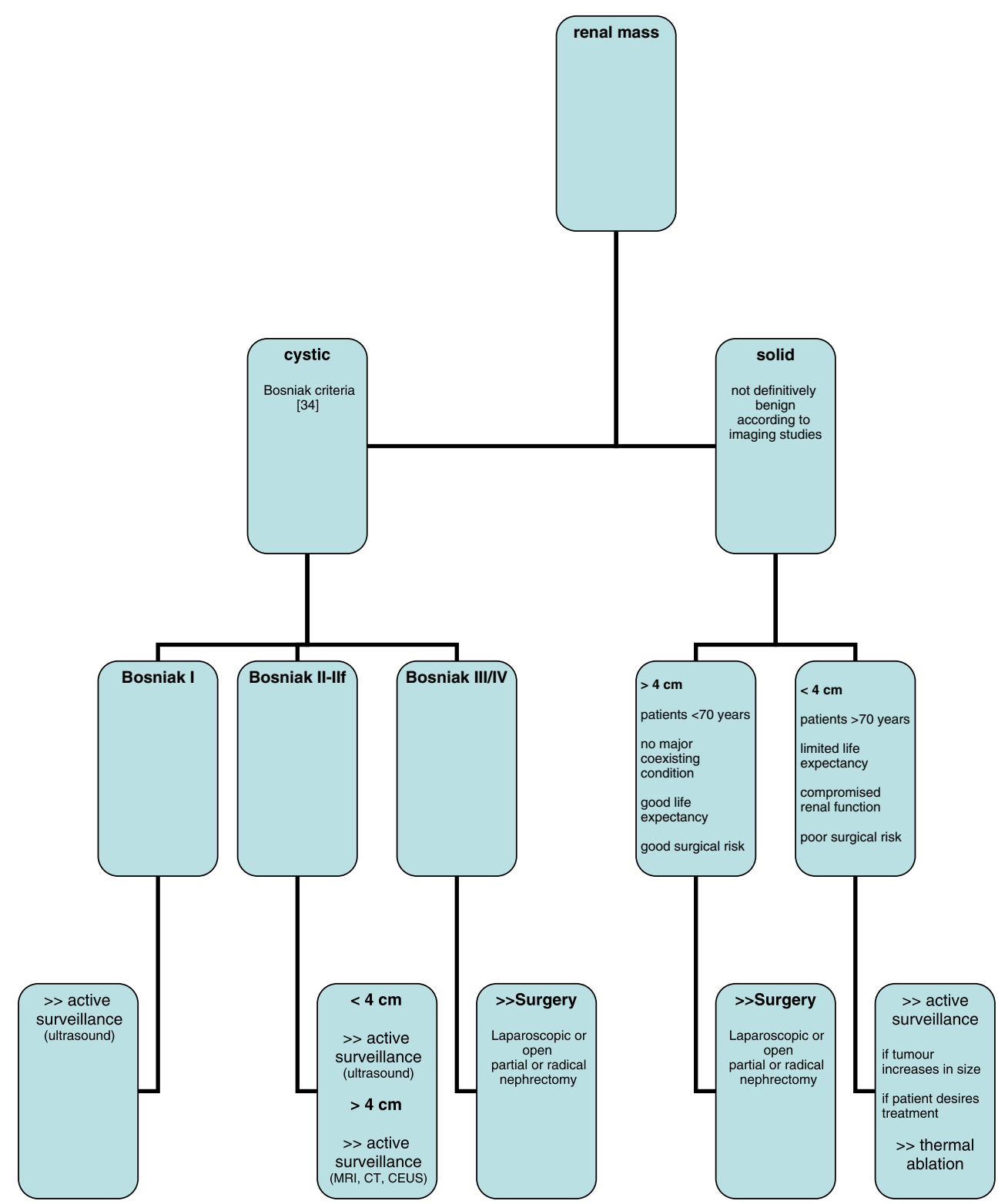


Imaging can help to support clinical management in patients with renal masses by depicting certain lesions that do not require treatment. MRI and CT are useful for followup, and helpful for planning specific surgical approaches. In unclear solid lesions a percutaneous renal mass biopsy (RMB) has to be considered. The use of RMB has increased in recent years, despite concerns about safety, accuracy and sampling errors [19]. New biopsy techniques decrease the risk of tumour seeding, and overall morbidity is low. Diagnostic sufficiency and accuracy of RMB are now much higher in large-volume, experienced centres [56, 57]. Experienced users can achieve accurate diagnosis in over $90 \%$. Pretreatment RMB can significantly decrease the number of unnecessary surgeries for benign disease and assist in clinical decision-making, beyond documenting renal involvement for patients with metastatic disease or other systemic illnesses. Especially for elderly and unfit patients who are possible candidates for active surveillance and/or minimally invasive ablative therapies, RMB seems to be a valuable tool. Finally, there is the potential for stratifying the initial therapy of metastatic RCC by histological subtype on needle biopsies [58]. Another study group concluded that percutaneous renal needle core biopsy has an acceptable sensitivity and specificity in the diagnosis of renal masses. The major limitation of percutaneous core biopsy is the technical failure that leads to insufficient material for accurate diagnosis [56, 57].

Furthermore, diagnostic and therapeutic decisions depend on the age and condition of the patient (see Fig. 11).

\section{Conclusion}

The technical developments in CT and MRI in the last decade enable an excellent detection rate of renal masses. Contrast-enhanced images allow differentiation between cystic and solid renal lesions. Complex cystic and solid lesions can be characterised further. Pretreatment percutaneous biopsy can significantly decrease the number of unnecessary surgeries for benign disease and assist the urologist in clinical decision-making, especially for elderly and unfit patients who are possible candidates for active surveillance and/or minimally invasive ablative therapies.

Acknowledgement Special thanks to Siegfried Schwab from the University Hospital Erlangen, Germany, for providing us with CT cases of renal lymphoma.

\section{References}

1. Srougi V, Kato RB, Salvatore FA, Ayres PP, Dall'Oglio MF, Srougi $M$ (2009) Incidence of benign lesions according to tumor size in solid renal masses. Int Braz J Urol 35(4):427-431
2. Coulam CH, Sheafor DH, Leder RA, Paulson EK, DeLong DM, Nelson RC (2000) Evaluation of pseudoenhancement of renal cysts during contrast-enhanced CT. AJR Am J Roentgenol 174 (2):493-498

3. Tada S, Yamagishi J, Kobayashi H, Hata Y, Kobari T (1983) The incidence of simple renal cyst by computed tomography. Clin Radiol 34:437-439

4. Pahernik S, Ziegler S, Roos F, Melchior SW, Thüroff JW (2007) Small renal tumors: correlation of clinical and pathological features with tumor size. J Urol 178:414-417, discussion 416-417

5. Jemal A, Siegel R, Ward E, Hao Y, Xu J, Murray T et al (2008) Cancer statistics, 2008. CA Cancer J Clin 58:71-96

6. Chow WH, Devesa SS, Warren JL, Fraumeni JF Jr (1999) Rising incidence of renal cell cancer in the United States. JAMA 281:1628-1631

7. D'Antonio A, Caleo A, Caleo O, Addesso M, Boscaino A (2010) Hepatocellular carcinoma metastatic to the kidney mimicking renal oncocytoma. Hepatobiliary Pancreat Dis Int 9(5):550-552

8. Kovacs G, Akhtar M, Beckwith BJ et al (1997) The Heidelberg classification of renal cell tumours. J Pathol 183:131-133

9. Motzer RJ, Bacik J, Mariani T, Russo P, Mazumdar M, Reuter V (2002) Treatment outcome and survival associated with metastatic renal cell carcinoma of non-clear-cell histology. J Clin Oncol 20:2376-2381

10. Choh NA, Jehangir M, Choh SA (2010) Renal replacement lipomatosis: a rare type of renal pseudotumor. Indian J Nephrol 20 (2):92-93

11. Tarhan F, Gül AE, Karadayi N, Kuyumcuoğlu U (2004) Inflammatory pseudotumor of the kidney: a case report. Int Urol Nephrol 36(2):137-140

12. Joffe SA, Servaes S, Okon S, Horowitz M (2003) Multi-detector row CT urography in the evaluation of hematuria. Radiographics 23(6): 1441-1455

13. Zhang J, Pedrosa I, Rofsky NM (2003) MR techniques for renal imaging. Radiol Clin North Am 41:877-907

14. Silverman SG, Leyendecker JR, Amis ES Jr (2009) What is the current role of CT urography and MR urography in the evaluation of the urinary tract? Radiology 250(2):309-323

15. Nikken JJ, Krestin GP (2007) MRI of the kidney - state of the art. Eur Radiol 17:2780-2793, Review

16. Al-Okaili RN, Krejza J, Wang S, Woo JH, Melhem ER (2006) Advanced MR imaging techniques in the diagnosis of intraaxial brain tumors in adults. Radiographics 26(Suppl 1): S173-S189

17. Zhang J, Tehrani YM, Wang L, Ishill NM, Schwartz LH, Hricak H (2008) Renal masses: characterization with diffusion-weighted MR imaging - a preliminary experience. Radiology 247(2): 458-464

18. Sandrasegaran K, Sundaram CP, Ramaswamy R, Akisik FM, Rydberg MP, Lin C, Aisen AM (2010) Usefulness of diffusionweighted imaging in the evaluation of renal masses. AJR Am J Roentgenol 194(2):438-445

19. Gill IS, Aron M, Gervais DA, Jewett MAS (2010) Small renal mass. N Engl J Med 362:624-634

20. Kreft BP, Müller-Miny H, Sommer T, Steudel A, Vahlensieck M, Novak D, Müller BG, Schild HH (1997) Diagnostic value of MR imaging in comparison to $\mathrm{CT}$ in the detection and differential diagnosis of renal masses: ROC analysis. Eur Radiol 7(4): 542-547

21. Frank I, Blute ML, Cheville JC, Lohse CM, Weaver AL, Zincke H (2003) Solid renal tumors: an analysis of pathological features related to tumor size. J Urol 170:2217-2220

22. Chawla SN, Crispen PL, Hanlon AL, Greenberg RE, Chen DY, Uzzo RG (2006) The natural history of observed enhancing renal masses: meta-analysis and review of the world literature. J Urol $175: 425-431$ 
23. Klatte T, Patard JJ, de Martino M et al (2008) Tumor size does not predict risk of metastatic disease or prognosis of small renal cell carcinomas. J Urol 179:1719-1726

24. Remzi M, Ozsoy M, Klingler HC et al (2006) Are small renal tumors harmless? Analysis of histopathological features according to tumors $4 \mathrm{~cm}$ or less in diameter. J Urol 176:896-899

25. Schurich M, Pallwein L, Steiner H, Mallouhi A, zur Nedden D, Frauscher F (2005) The role of Multiphasic Helical CT in estimation of type of renal cell carcinoma: an approach based on standardized morphological and enhancement parameters (abstract for poster presentation LPH06-04) In: Radiological Society of North America scientific assembly and annual meeting program. Oak Brook, IL. Available at http://rsna2005.rsna.org/rsna2005/ V2005/conference/event_display.cfm?em_id $=4419040$

26. Siu W, Hafez KS, Johnston WK III, Wolf JS Jr (2007) Growth rates of renal cell carcinoma and oncocytoma under surveillance are similar. Urol Oncol 25:115-119

27. Kunkle DA, Crispen PL, Chen DYT, Greenberg RE, Uzzo RG (2007) Enhancing renal masses with zero net growth during active surveillance. J Urol 177:849-854

28. Silverman SG, Israel GM, Herts BR, Richie JP (2008) Management of the incidental renal mass. Radiology 249:16-31

29. Kim JK, Kim SH, Jang YJ et al (2008) Renal angiomyolipoma with minimal fat: differentiation from other neoplasms at doubleecho chemical shift FLASH MR imaging. Radiology 239: 174-180

30. Israel GM, Bosniak MA (2008) Pitfalls in renal mass evaluation and how to avoid them. Radiographics 28(5):1325-1338, Review

31. Outwater EK, Bhatia M, Siegelman ES, Burke MA, Mitchell DG (1997) Lipid in renal clear cell carcinoma: detection on opposedphase gradient-echo MR images. Radiology 205:103-107

32. Pedrosa I, Sun MR, Spencer M, Genega EM, Olumi AF, Dewolf WC, Rofsky NM (2008) MR imaging of renal masses: correlation with findings at surgery and pathologic analysis. Radiographics 28:985-1003

33. Wagner BJ (1997) The kidney: radiologic-pathologic correlation. Magn Reson Imaging Clin N Am 5:13-28

34. Israel GM, Hindman N, Bosniak MA (2004) Evaluation of cystic renal masses: comparison of $\mathrm{CT}$ and MR imaging by using the Bosniak classification system. Radiology 231(2): 365-371

35. Koga S, Nishikido M, Inuzuka S, Sakamoto I, Hayashi T, Hayashi K, Saito Y, Kanetake H (2000) An evaluation of Bosniak's radiological classification of cystic renal masses. BJU Int 86 (6):607-609

36. Xu HX (2009) Contrast-enhanced ultrasound: the evolving applications. World J Radiol 31(1):15-24

37. Novara G, Martignoni G, Artibani W, Ficarra V (2007) Grading systems in renal cell carcinoma. J Urol 177:430-436

38. Cheville JC, Lohse CM, Zincke H, Weaver AL, Blute ML (2003) Comparisons of outcome and prognostic features among histologic subtypes of renal cell carcinoma. Am J Surg Pathol 27: 612-624

39. Ruppert-Kohlmayr AJ, Uggowitzer M, Meissnitzer T, Ruppert G (2004) Differentiation of renal clear cell carcinoma and renal papillary carcinoma using quantitative CT enhancement parameters. AJR Am J Roentgenol 183:1387-1391
40. Roy C, Sauer B, Lindner V, Lang H, Saussine C, Jacqmin D (2007) MR imaging of papillary renal neoplasms: potential application for characterization of small renal masses. Eur Radiol 17:193-200

41. Yoshimitsu K, Kakihara D, Irie H et al (2006) Papillary renal carcinoma: diagnostic approach by chemical shift gradient-echo and echo-planar MR imaging. J Magn Reson Imaging 23:339-344

42. Vikram R, Sandler CM, Ng CS (2009) Imaging and staging of transitional cell carcinoma: part 2, upper urinary tract. AJR Am J Roentgenol 192(6):1488-14893, Review

43. Pickhardt PJ, Lonergan GJ, Davis CJ Jr, Kashitani N, Wagner BJ (2000) From the archives of the AFIP: infiltrative renal lesionsradiologic-pathologic correlation. Radiographics 20:215-243

44. Hulnick DH, Bosniak MA (1986) "Faceless kidney": CT sign of renal duplicity. J Comput Assist Tomogr 10:771-772

45. Sheth S, Ali S, Fishman E (2006) Imaging of renal lymphoma: patterns of disease with pathologic correlation. Radiographics 26 (4):1151-1168, Review

46. Urban BA, Fishman EK (2000) Renal lymphoma: CT patterns with emphasis on helical CT. Radiographics 20:197-212

47. Semelka RC, Kelekis NL, Burdeny DA, Mitchell DG, Brown JJ, Siegelman ES (1996) Renal lymphoma: demonstration by MR imaging. AJR Am J Roentgenol 166:823-827

48. Pinggera GM, Peschel R, Buttazzoni A, Mitterberger M, Friedrich A, Pallwein L (2009) A possible case of primary renal lymphoma: a case report. Cases J 2:6233

49. Simpfendorfer C, Herts BR, Motta-Ramirez GA, Lockwood DS, Zhou M, Leiber M, Remer EM (2009) Angiomyolipoma with minimal fat on MDCT: can counts of negative-attenuation pixels aid diagnosis? AJR Am J Roentgenol 192(2):438-443

50. Israel GM, Hindman N, Hecht E, Krinsky G (2005) The use of opposed-phase chemical shift MRI in the diagnosis of renal angiomyolipomas. AJR Am J Roentgenol 184:1868-1872

51. Burdeny DA, Semelka RC, Kelekis NL, Reinhold C, Ascher SM (1997) Small $(<1.5 \mathrm{~cm})$ angiomyolipomas of the kidney: characterization by the combined use of in-phase and fatattenuated MR techniques. Magn Reson Imaging 15:141-145

52. Harmon WJ, King BF, Lieber MM (1996) Renal oncocytoma: magnetic resonance imaging characteristics. J Urol 155:863-867

53. Verswijvel G, Oyen R, Van Poppel H, Roskams T (2000) Xanthogranulomatous pyelonephritis: MRI findings in the diffuse and the focal type. Eur Radiol 10:586-589

54. Craig WD, Wagner BJ, Travis MD (2008) Pyelonephritis: radiologic-pathologic review. Radiographics 28(1):255-277, quiz 327-328. Review

55. Jeong JY, Kim SH, Lee HJ, Sim JS (2002) Atypical lowsignal-intensity renal parenchyma: causes and patterns. Radiographics 22(4):833-846, Review

56. Wang R, Li AY, Wood DP Jr (2011) The role of percutaneous renal biopsy in the management of small renal masses. Curr Urol Rep 12(1):18-23

57. Sofikerim M, Tatlisen A, Canoz O, Tokat F, Demirtas A, Mavili E (2010) What is the role of percutaneous needle core biopsy in diagnosis of renal masses? Urology 76(3):614-618

58. Volpe A, Terrone C, Scarpa RM (2009) The current role of percutaneous needle biopsies of renal tumours. Arch Ital Urol Androl 81(2):107-112, Review 